\title{
COMPARISON OF TAX REVENUE FORECASTING MODELS FOR TURKEY
}

\author{
Hamza ERDOĞDU ${ }^{1}$
}

\author{
Recep YORULMAZ
}

\begin{abstract}
The objective of this study is to compareperformance of threeforecasting tax revenue models for Turkeyover the period of 2006: 01 to 2018: 12. Three different time series forecasting techniques such as Random Walk, SARIMA (Seasonal Autoregressive Integrated Moving Average) and BATS (Exponential Smoothing State Space Model with Box-Cox Transformation, ARMA Errors, Trend and Seasonal Components) are used in the study. At the beginning of the analysis, the data set was apportioned into two parts: training and testing. The training period is from 2006: 01 to 2014: 12 and the testing part is from 2015: 01 to 2018: 12. Based on different evaluation criteria, forecast points of 36 months are obtained for each forecasting model. We find that using the BATS model, rather than classical S(ARIMA) in forecasting series of monthly tax revenues of Turkey, provide more accurate forecasts. The empirical findings of this study help the experts in the preparation process of government's budgets.
\end{abstract}

Keywords: Forecasting,Tax Revenue, BATS, SARIMA, Turkey

JEL Code: $\mathrm{C} 1, \mathrm{C} 5, \mathrm{H} 20$.

\section{Introduction}

Tax revenues are considered amongst the fundamental sources of governments budget planning. Governments collect taxes not only to finance their expenses but also aiming of stabilization, distribution and allocation in the economy. They use taxes to stabilize the employment levels, balance of payments and/or prizes. They might try to intervene the income and wealth distribution by playing with the tax structure. Further, they might want to use taxes to allocation of resources in the economy by using their allocative effects on certain goods (Brown \& Jackson, 1986: 297).

There are three fundamental classifications in Turkish tax system. These are income taxes, taxes on expenditure and taxes on wealth. The relative importance of these taxes in the Turkish tax system is presented in Table 1 . Income taxes are classified as individual income and corporate income taxes. Income taxes yield about $30 \%$ of total revenues in Turkish tax system.

\footnotetext{
1 Asst. Prof. Dr., Harran University, Faculty of Economics and Administrative Sciences, Department of Econometrics, hamzaerdogdu@harran.edu.tr

2 Asst. Prof. Dr., Ankara Yıldırım Beyazıt University, Faculty of Political Sciences, Department of Public Finance, ryorulmaz@ybu.edu.tr
} 
Table 1. Percentage Distribution of Tax Revenues in Turkey

\begin{tabular}{lrrrrr} 
& $\mathbf{2 0 0 8}$ & $\mathbf{2 0 0 9}$ & $\mathbf{2 0 1 0}$ & $\mathbf{2 0 1 1}$ & $\mathbf{2 0 1 2}$ \\
\hline Income Taxes & $\mathbf{3 1 , 3}$ & $\mathbf{3 1 , 8}$ & $\mathbf{2 8 , 4}$ & $\mathbf{2 9 , 1}$ & $\mathbf{2 9 , 7}$ \\
Personal Income Taxes & 21,2 & 20,9 & 18,4 & 18,5 & 19,2 \\
Corporate Income Taxes & 10,1 & 10,9 & 10 & 10,6 & 10,5 \\
\hline Taxes on Expenditure & $\mathbf{6 6 , 5}$ & $\mathbf{6 5 , 4}$ & $\mathbf{6 9}$ & $\mathbf{6 8 , 6}$ & $\mathbf{6 7 , 9}$ \\
Value Added Tax & 32,5 & 31,7 & 33,2 & 34,7 & 33,6 \\
Special Consumption Tax & 22,7 & 23 & 25,4 & 23,3 & 23,4 \\
Banking and Insurance & & & & & \\
Transaction Taxes & 2 & 2,1 & 1,6 & 1,6 & 1,8 \\
Stamp Duty Tax & 2,2 & 2,2 & 2,3 & 2,4 & 2,4 \\
Special Communication Tax & 2,5 & 2,3 & 1,8 & 1,6 & 1,5 \\
Tax on Wagering & 0,2 & 0,2 & 0,2 & 0,2 & 0,2 \\
Tax on Customs & 1,5 & 1,3 & 1,4 & 1,7 & 1,7 \\
\hline Taxes on Wealth & $\mathbf{2 , 3}$ & $\mathbf{2 , 5}$ & $\mathbf{2 , 3}$ & $\mathbf{2 , 3}$ & $\mathbf{2 , 3}$ \\
Inheritance and Gift Taxes & 0,1 & 0,1 & 0,1 & 0,1 & 0,1 \\
Motor Vehicle Tax & $\mathbf{2 , 2}$ & $\mathbf{2 , 4}$ & $\mathbf{2 , 2}$ & $\mathbf{2 , 2}$ & $\mathbf{2 , 2}$ \\
\hline
\end{tabular}

Source: Saracoglu et. al. (2014)

Taxes on expenditures, on the other hand, contain approximately $68 \%$ of total revenues in Turkish tax system. Taxing expenditures is considered as the common and easy way to collect taxes for governments. Hence, that big amount of taxes is comprised of expenditures in Turkey. Finally, taxes on wealth only yield approximately $2 \%$ of total revenues.Tax analysis and forecasting of tax revenues for governments are crucial to ensure stability in tax and expenditure policies (Jenkins et. al., 2000).

Budgetary uncertainties directed governments to rely heavily on economic analysis in recent decades. Because of the extent of these fiscal problems forecasting tax revenues is essential for governments to manage their budget planning process. Recent fiscal problems of governments created reliability issues on economic and revenue forecasting. Hence, there are plenty of methods that are used to forecast tax revenues by policymakers (Fullerton, 1989). Transparency and accuracy are the key components while determining the method for forecasting. A potential manipulation of forecasts might create government problems.

Furthermore, inaccurate forecasts might hinder abilities of policymakers to make accurate budget planning and harm levels of productivity in the economy (Kyobe and Danninger, 2005; Cirincione et al., 1999). It is considered that countries with high-income levels and relatively small central government tend to have high formality, accuracy and transparency forecasts (Kyobe and Danninger, 2005).

Government revenue forecasting studies for Turkey are rare in the literature; hence this study aims to fill this gap. The rest of the study is organized as follows. Section II outlines the major studies that make forecasting analysis in the literature. Furthermore, Section III describes the methodologies of the forecasting techniques applied and the data that are used in the study. Section IV provides the outcomes of selected forecasting methods in the study. Finally, Section $\mathrm{V}$ contains the conclusion and discussions. 


\section{Literature}

Majority of forecasting studies focused on the private sector in the literature so far, hence the studies focused on government revenue are relatively less than private sector studies. For instance, Gajewar and Bansal (2016) conducted forecasting analysis for private sector using machine-learning algorithms. Specifically, they performed ARIMA, ETS (Exponential Smoothing), STL (Seasonal and Trend Decomposition using Loess), and Random forest machine-learning algorithms to obtain revenue forecast for Microsoft. They suggested that using machine-learning algorithms methods would increase the accuracy of quarterly revenue forecasting.

Many researchers also focused on state and/or municipal revenue forecasting analysis so far. Fullerton (1989) analyzed sales tax revenues using composite forecasting modelfor Idaho. Using time series model and econometric models he examined the capability of composite forecasting model. He found that the composite forecast model are more effective than base line forecasts. The combined model was also found more accurate than previous forecast attempts for Idaho.

Hamboret. al. (1974) used econometric forecasting method using simple revenue structurefor Hawaii. They forecasted state revenues including; excise, personal income, corporate income, and other state tax revenues, for a single fiscal year of Hawaii. Furthermore, Kyobe and Danninger (2005) analyzed the revenue forecasting practices in 34 low-income countries focusing especially on institutional prospects. They claimed that there are three key factors on forecasting practices such as "formality, organizational simplicity, and transparency". They empirically found that countries levels of corruption are Assoc.d with formality and transparency of forecasting. Accordingly, they found that high levels of corruption are related with less formal and transparent forecasts.

Cirincione et al. (1999) examined the impact of using time series models, the length and the frequency of the data on non-tax general fund revenue forecasting for the municipalities of Connecticut. They found that exponential smoothing models are most effective on bimonthly data in which they claim local governments should rely on rather than monthly or quarterly data.

As we pointed above, there are plenty of methods that were used to forecast private sector or government/state/municipal revenues in the literature. It is also important to analyze the methods used in these studies. In case of the Box-Jenkins AutoRegressive Integrated Moving Average Model (ARIMA), researchers found different results in effectiveness of ARIMA model. For instance, Makridakis and Hibon(1995) claimed that the ARIMA model performs relatively poor than other models. In doing so, Makridakis et al. (1979) found the reason of this poor performance of ARIMA model as usage of differencing in order to find stationary in the mean of the series.

Similarly, in a series of studies that focused on local government revenue forecasting for the municipalities of Florida, researchers found similar results. They claimed that Box-Jenkins ARIMA model performs poorly than other methods such as time series models, which produce lower forecast errors. Furthermore, they found that trend fitting by regression generated more forecast errors than its counterpart methods (Frank and Gianakis,1990;Gianakis and Frank, 1993).

It is important to point out that the studies that found poor performance for ARIMA method mainly focused on municipal government revenue forecasting. Differently, Downs and Rock (1983) found evidence that multivariate AutoRegressive Moving Average (ARMA) method is more effective than univariate techniques using ARMA model for municipal government revenue forecasting. 
While, most of the forecasting studies examine relative performance of various methods so far, only few researchers tested the impact of data quality on the performance of forecasting methods. Gianakis and Frank (1993), which is one these studies, claimed that the length of the data does not have any impact on the accuracy of forecasting techniques. However, some scholars suggested that at least fifty observations are necessary to implement the Box-Jenkins ARIMA method. On the other hand, scholars have kept using this method with fewer numbers so far (Lorek et al., 1976).

Lorek and McKeown (1978) analyzed the association between observation numbers and the performance of the Box-Jenkins method on quarterly market income data. They found that the forecast error is not significantly different in models based on fifty observations and models based on fewer observations. They suggested that if the number of observations of Box-Jenkins method decreases, forecast error increases. However, the performance of the model does not Assoc.d with the number of observations at least until twenty-four or fewer observations. Similarly, Lusk and Neves (1984) found a result consistent with the previous cases. They suggested that the performance of the Box-Jenkins model does not Assoc.d with the length of data or the frequency in their private sector study.

\section{Data and Methodology}

\subsection{Data}

In the analysis, the series of monthly tax revenues in the central government budget realisations, from January 2006 to December 2018 is used. The data is obtained from the web site of General Directorate of Budget and Fiscal Control (BÜMKO). The series is plotted and shown in Figure 1, provides also some descriptive statistics about the data to help better understanding the structure of the series. From the plot, it is clear that the series has trend and seasonal component.

Figure 1.TurkeyTaxRevenues, 2006M01 - 2018M12

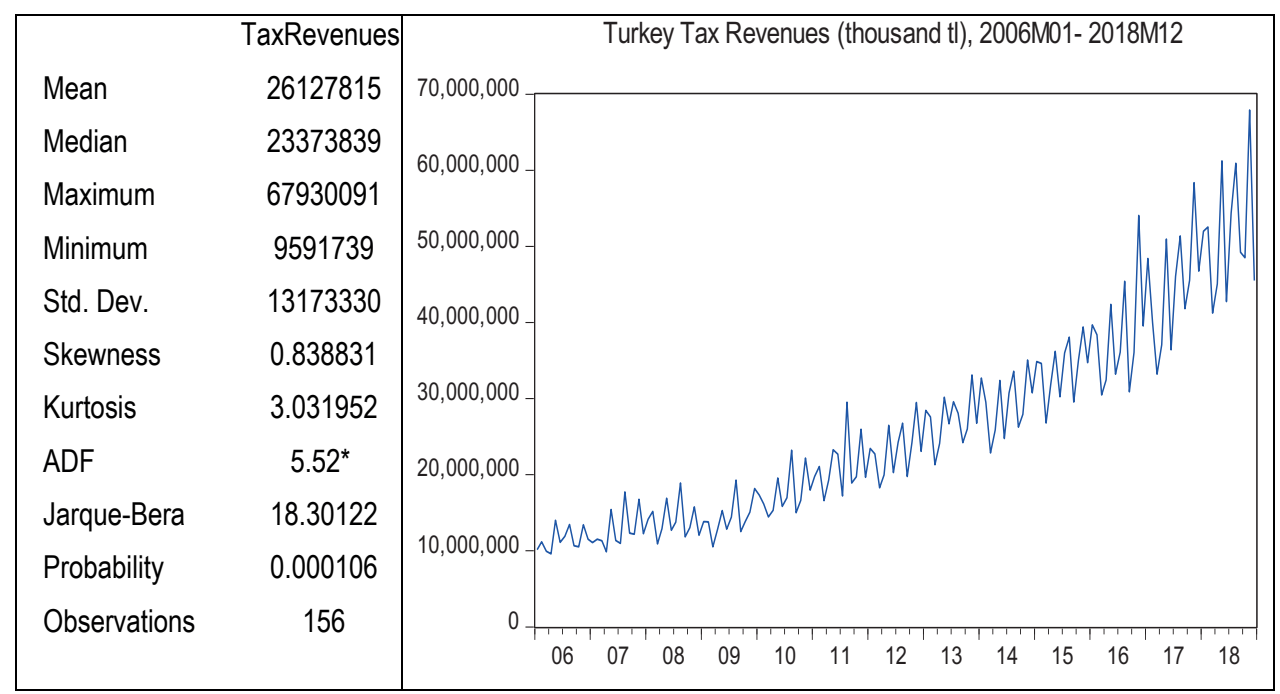

Source: General Directorate of Budget and Fiscal Control and General Directorate of Budget and Fiscal Control. * the $t \square$ statistic value of the Augmented Dickey-Fuller test, indicating nonstationarity of the series at level 0.05 . 


\subsection{Methodology}

In this section, we provide the fundamentals of the forecasting methods used in the study such as: Random Walk, SARIMA and BATS.

\subsubsection{Random Walk-RW}

Random walk model is widely used in econometric forecasting studies as a benchmark.

A time series is said to follow a random walk process if the first differences are random.

For a time series $Y_{t}$, a random walk can be written as differences changes from one period to the next,

$$
Y_{t}=Y_{t-1}+\varepsilon_{t}
$$

where $Y_{t-1}$ is the value at time $t-1$ and $\varepsilon_{t}$ is a discrete white noise at time $t$.

\subsubsection{SARIMA}

Introduced by Box and Jenkins (1970) ARIMA (Auto-Regressive Integrated Moving Average) models are a broad category of univariate models. In forecasting a time series, these models bring together three components: the auto-regressive (AR), the moving average (MA) part and the integrated (I) part. The AR part indicates that individual values in a variable of interest can be described by linear models based on its own lagged values. The MA part assumes that regression error is a linear combination error terms. The integrated part (I) shows the degree of differencing.

The ARMA (AutoRegressive, MovingAverage) model is defined as follows:

$$
Y_{t}=\varphi_{1} Y_{t-1}+\varphi_{2} Y_{t-2}+\ldots+\varphi_{p} Y_{t-p}+\alpha_{t}-\psi_{1} \alpha_{t-1}-\psi_{2} \alpha_{t-2}-\ldots-\psi_{q} \alpha_{t-q}
$$

where the $Y_{t}^{\prime} s$ are the original time series, the $\varphi^{\prime} s$ are the unknown autoregressive parameters, the $\psi$ ' $s$ are the unknown moving average parameters and the a ' $s$ are the white noise error terms.

A modification for nonstationary series, known as $\operatorname{ARIMA}(p, d, q)$ is;

$$
\varphi_{p}(B)(1-B)^{d} Y_{t}=\psi_{q}(B) \alpha_{t}
$$

where $B$ is the backshift operator, thus $B Y_{t}=Y_{t-1}$ and $B^{2} Y_{t}=Y_{t-2}$ and the $d$ parameter indicates the order of differencing.

For seasonal series, a more general form of above equation, and known as the multiplicative seasonal ARIMA -SARIMA $(p, d, q)(P, D, Q)_{s}$ process is given by;

$$
\phi_{p}(B) \Phi_{P}(B)(1-B)^{d}\left(1-B^{s}\right)^{D} Y_{t}=\psi_{q}(B) \Theta_{Q}\left(B^{s}\right) \alpha_{t}
$$


where $\left(1-B^{s}\right) Y_{t}=Y_{t}-Y_{t-s}$ and ${ }^{S}$ is the number of seasons per year, $\left(1-B^{s}\right), d$ and $D$ are the orders of differencing. Also $\varphi_{p}, \Phi_{P}, \psi_{q}$ and $\Theta_{Q}$ are the polynomial functions of orders $p, P, q$ and $Q$, respectively.

\subsubsection{BATS}

To model series having only one seasonal pattern, Winters (1960) introduces the standard HoltWinters method. However, Taylor(2003) extends the standard method to a double seasonal Holt-Winters method, following mainly De Livera et. al (2012);

$$
\begin{aligned}
& Y_{t}=L_{t-1}+B_{t-1}+S_{t}^{(1)}+S_{t}^{(2)}+D_{t}, \\
& L_{t}=L_{t-1}+B_{t-1}+\alpha D_{t}, \\
& B_{t}=B_{t-1}+\beta D_{t}, \\
& S_{t}^{(1)}=S_{t-k_{1}}^{(1)}+\lambda_{1} D_{t}, \\
& S_{t}^{(2)}=S_{t-k_{2}}^{(1)}+\lambda_{2} D_{t},
\end{aligned}
$$

where $L_{t}$ represents the level component of the series $Y_{t}$ at time $t$,

$B_{t}$ represents the trend component of the series $Y_{t}$ at time $t$,

$S_{t}^{(i)}$ represents the ${ }^{i}$ th seasonal companent at time $t$,

$k_{1}$ and $k_{2}$ are the periods of the seasonal cycles,

$D_{t}$ is the disturbance (or prediction error),

$\alpha, \beta, \lambda_{1}$ and $\lambda_{2}$ are the smoothing parameters,

Proposed by De Livera et. al (2012), the BATS models (Exponential Smoothing State Space Model with Box-Cox Transformation, ARMA Erorrs, Trend and Seasonal Components) are designed in the exponential smoothing framework. The models are constructed to handle more than one seasonality as well as complex seasonalities for example, non-nested, non-integer and large period seasonality. De Livera et. al (2012) extends the double seasonal Holt-Winters method by adding a Box-Cox transformation, ARMA errors, and $T$ seasonal patterns:

$$
\begin{aligned}
& Y_{t}^{(w)}=\left\{\begin{array}{l}
\frac{Y_{t}^{w}-1}{w}, w \neq 0, \\
\log Y_{t}, w=0,
\end{array}\right. \\
& Y_{t}^{(w)}=L_{t-1}+\varphi B_{t-1}+\sum_{i=1}^{T} S_{t-k_{i}}^{(i)}+D_{t}, \\
& L_{t}=L_{t-1}+\varphi B_{t-1}+\alpha D_{t}, \\
& B_{t}=(1-\varphi) B+\varphi B_{t-1}+\beta D_{t},
\end{aligned}
$$




$$
\begin{aligned}
S_{t}^{(i)} & =S_{t-k_{i}}^{(i)}+\lambda_{i} D_{t}, \\
D_{t} & =\sum_{i=1}^{p} \psi_{i} D_{t-1}+\sum_{i=1}^{q} \zeta_{i} \eta_{t-i}+\eta_{t},
\end{aligned}
$$

where; $L_{t}$ represents the local level in period $t$,

$B_{t}$ represents the short-run trend in period $t$,

$B$ represents the long-run trend in period $t$,

$\varphi$ represents the damping parameter,

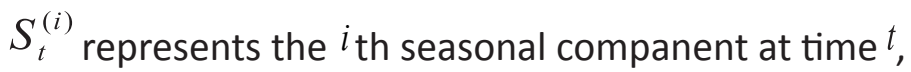

$k_{1}, k_{2}, \ldots, k_{T}$ are the seasonal periods,

$D_{t}$ is an $\operatorname{ARMA}(p, q)$ process,

$\eta_{t}$ is a Gaussian process with zero mean and constant variance $\sigma^{2}$,

$\alpha, \beta, \lambda_{1}$ and $\lambda_{2}$ are the smoothing parameters,

\section{Analysis and Emprical Results}

At the beginning of the analysis, we split the data into a training and testing set. The training set covers the period from 2006:01 to 2014:12 and the testing part covers the period from 2015:01 to 2018:12. The training data set is used to only to estimate unknown model parameters. Once the model coefficients are estimated, forecasts for each model are made for the testing part. To evaluate forecast accuracy of each model, the testing data is used.

The resuts of the best $\operatorname{ARIMA}(0,1,2)(0,1,1)^{\mathbb{2}}$ model for the tax revenues series is given in the following Table 2. Automatic ARIMA selection option was used in the forecast package in $R$, the details can be found in Hyndman and Khandahar (2008).

Table 2. The results of the ARIMA $(0,1,2)(0,1,1) 12$ model

\begin{tabular}{|c|c|c|c|}
\hline & Lagged length & Coefficints & Standard Error \\
\hline MA & 1 & -1.0682 & 0.0963 \\
\hline MA & 2 & 0.3932 & 0.0969 \\
\hline SMA & & -0.4693 & 0.0908 \\
\hline
\end{tabular}

The results of the BATS $(0.377,\{0,0\}, 1,\{12\})$ model for the series is provided in Table 3 . The forecast package in $\mathrm{R}$ is used to get the results. 
Table 3. The results of the BATS $(0.377,\{0,0\}, 1,\{12\})$ Model

\begin{tabular}{|c|c|}
\hline Parameters & Coefficients \\
\hline Lambda & 0.376905 \\
\hline Alpha & 0.2432854 \\
\hline Beta & 0.01566971 \\
\hline Damping & 1 \\
\hline Gamma Values & -0.1082185 \\
\hline
\end{tabular}

After fitting three time series models: random walk, SARIMA and BATS, forecasts for the testing period, 2015: 01 to 2018: 12, are obtained in Table 4.

Finally, accuracy of each model is measured on the testing set. Table 5, provides statistical measures of accuracy of each method based on various forecast evaluation criteria: ME, RMSE, MAE, MPE, MAPE, MASE and Theil's U.

Table 4. Point Forecasts of the Methods for the Testing Data (2016M01-2018M12)

\begin{tabular}{|c|c|c|c|c|}
\hline \multirow{2}{*}{ Forecast Horizon } & & \multicolumn{3}{|c|}{ Forecasting Methods } \\
\cline { 3 - 5 } & ACTUAL & Random Walk & SARIMA & BATS \\
\hline Jan 2016 & 39685212 & 34729587 & 39551109 & 38989627 \\
\hline Feb 2016 & 38361380 & 34729587 & 38414335 & 37396828 \\
\hline Mar 2016 & 30496694 & 34729587 & 31463837 & 30878845 \\
\hline Apr 2016 & 32446011 & 34729587 & 35440194 & 34802877 \\
\hline May 2016 & 42368600 & 34729587 & 40607697 & 41212156 \\
\hline Jun 2016 & 33195345 & 34729587 & 34699758 & 35611013 \\
\hline Jul 2016 & 36111701 & 34729587 & 39678120 & 38694089 \\
\hline Aug 2016 & 45425215 & 34729587 & 41889999 & 43894982 \\
\hline Sep 2016 & 30883849 & 34729587 & 34262776 & 34663442 \\
\hline Oct 2016 & 36060795 & 34729587 & 38123593 & 38056660 \\
\hline Nov 2016 & 54060129 & 34729587 & 43576351 & 44574433 \\
\hline Dec 2016 & 39906810 & 34729587 & 38712079 & 38555889 \\
\hline Jan 2017 & 48420673 & 34729587 & 43405126 & 43683557 \\
\hline Feb 2017 & 39994384 & 34729587 & 42309290 & 41972917 \\
\hline Mar 2017 & 33201256 & 34729587 & 35358791 & 34951174 \\
\hline Apr 2017 & 37082457 & 34729587 & 39335148 & 39182860 \\
\hline May 2017 & 50949456 & 34729587 & 44502651 & 46067487 \\
\hline Jun 2017 & 36422643 & 34729587 & 38594712 & 40052674 \\
\hline Jul 2017 & 46062984 & 34729587 & 43573075 & 43366295 \\
\hline Aug 2017 & 51377479 & 34729587 & 45784953 & 48940777 \\
\hline Sep 2017 & 41837993 & 34729587 & 38157730 & 39032728 \\
\hline Oct 2017 & 45559415 & 34729587 & 42018548 & 42681794 \\
\hline Nov 2017 & 58372034 & 34729587 & 47471306 & 49667752 \\
\hline
\end{tabular}




\begin{tabular}{|c|l|l|l|l|}
\hline Dec 2017 & 46766884 & 34729587 & 42607034 & 43217915 \\
\hline Jan 2018 & 51995609 & 34729587 & 47300081 & 48714507 \\
\hline Feb 2018 & 52558220 & 34729587 & 46204244 & 46882727 \\
\hline Mar 2018 & 41249512 & 34729587 & 39253745 & 39342516 \\
\hline Apr 2018 & 45049034 & 34729587 & 43230102 & 43890960 \\
\hline May 2018 & 61218542 & 34729587 & 48397605 & 51264277 \\
\hline Jun 2018 & 42749559 & 34729587 & 42489666 & 44824230 \\
\hline Jul 2018 & 54360053 & 34729587 & 47468029 & 48374916 \\
\hline Aug 2018 & 60934207 & 34729587 & 49679907 & 54333154 \\
\hline Sep 2018 & 49235735 & 34729587 & 42052684 & 43729821 \\
\hline Oct 2018 & 48504135 & 34729587 & 45913502 & 47642028 \\
\hline Nov 2018 & 67930091 & 34729587 & 51366260 & 55108914 \\
\hline Dec 2018 & 45525901 & 34729587 & 46501988 & 48216072 \\
\hline
\end{tabular}

Table 5. Measures Accuracy of the Methods for Testing Set (2016M01-2018M12)

\begin{tabular}{|l|c|c|c|c|c|c|c|}
\hline Methods & ME & RMSE & MAE & MPE & MAPE & MASE & Theil's U \\
\hline $\begin{array}{l}\text { Random } \\
\text { Walk }\end{array}$ & 10159746.6 & 13580773 & 10905568 & 19.50 & 21.87 & 3.93 & 1.27 \\
\hline SARIMA & 2961666.3 & 5761357 & 4317229 & 4.84 & 8.73 & 1.56 & 0.55 \\
\hline BATS & $\mathbf{2 0 4 2 8 6 4 . 3}$ & $\mathbf{4 5 7 8 1 4 4}$ & $\mathbf{3 5 8 3 7 6 8}$ & $\mathbf{3 . 1 3}$ & $\mathbf{7 . 4 3}$ & $\mathbf{1 . 2 9}$ & $\mathbf{0 . 4 4}$ \\
\hline
\end{tabular}

The measures calculated are: ME: Mean Error, RMSE: Root Mean Squared Error, MAE: Mean Absolute Error, MPE: Mean Percentage Error, MAPE: Mean Absolute Percentage Error, MASE: Mean Absolute Scaled Error, Theil's U: Theil Inequality Coefficient.

Among the three generated models, the accuracies of the models are tested based on seven forecast evaluation criteria. From the Table 5 results, BATS is preferred asthe best forecasting model for the tax revenues series of Turkey, since it provides lesser values of seven evaluation criteria: ME, RMSE, MAE, MPE, MAPE, MASE and Theil's U.

\section{Conclusion}

The aim of this study is to evaluate performance of three forecasting tax revenue models for Turkey over the period of 2006: 01 to 2018: 12. Three different time series forecasting techniques such as Random Walk, SARIMA (Seasonal Autoregressive Integrated Moving Average) and BATS (Exponential Smoothing State Space Model with Box-Cox Transformation, ARMA Erorrs, Trend and Seasonal Components) are used in the study. At the beginning of the analysis, the data set was apportioned into two parts:training and testing. The training period is from 2006: 01 to 2014: 12 and the testing part is from 2015:01 to 2018:12. Based on different evaluation criteria, forecast points of 36 months are obtained for each forecasting model.

BATS model outperforms the benchmark RW and SARIMA models based on all evaluation criteria. We find that using the BATS model, rather than seasonal ARIMAYIImaz (2019) in forecating series of monthly tax revenues of Turkey, provide more accurate forecasts. The empirical findings of 
this study help the experts in the preparation process of government's budgets. For further forecasting of other tax types such as Corporate Income Tax, Value Added Tax and Total Tax, the BATS model may provide better performance. Also the empirical results of the current study will be used to develop combined forecasting models.

\section{References}

Box, G. E. P. \& Jenkins, G. (1970). Time Series Analysis, Forecasting and Control, Holden-Day, CA, USA, San Francisco.

Brown, C. V. \& Jackson, P. M. (1986). Public Sector Economics, Oxford, Blackwell Basil.

Cirincione, C., Gurrieri, G. A. \& Sande, B. (1999). "Municipal Government Revenue Forecasting: Issues of Method and Data", Public Budgeting and Finance, 19, pp. 26-46.

De Livera, A. M., Hyndman, R. J., \& Snyder, R. D. (2011). “Forecasting Time Series with Complex Seasonal Patterns Using Exponential Smoothing", Journal of the American Statistical Association, 106 (496), pp. 1513-1527.

Downs, G. W. \& Rocke, D. M. (1983). "Municipal Budget Forecasting with Multivariate ARMA Models", Journal of Forecasting, 2, pp. 377-387.

Frank, H. A. \& Gianakis, G. A. (1990). "Raising the Bridge Using Time Series Forecasting Models", Public Productivity \& Management Review, 14, pp. 171-188.

Fullerton, T. M. (1989). "A Composite Approach to Forecasting State Government Revenues: Case Study of The Idaho Sales Tax", International Journal of Forecasting, 5, pp. 373-380.

Gajawar, A. \& Bansal, G. (2016). "Revenue Forecasting for Enterprise Products", International Symposium on Forecasting, 2016.

Gianakis, G. A. \& Frank, H. A. (1993). "Implementing Time Series Forecasting Models: Considerations for Local Governments”, State \& Local Government Review, 25, pp. 130-144.

Hyndman, R. J. \& Khandakar, Y. (2008). Automatic Time Series Forecasting: The Forecast Package for R. Journal of Statistical Software, 27, pp. 1-22.

Hambor, J. C., Norman, M. R. \& Russell, R. R. (2016). "A Tax Revenue Forecasting Model for the State of Hawaii", Public Finance Quarterly, 2, pp. 432-450.

Kyobe, A. \& Danninger, S. (2005). "Revenue Forecasting: How is it Done? Results From a Survey of Low-Income Countries", IMF Working Papers. 05, p. 1.

Lorek, K. S., Mcdonald, C. L. \& Patz, D. H. (1976). "A Comparative Examination of Management Forecasts and Box-Jenkins Forecasts of Earnings", The Accounting Review, 51, pp. 321-330.

Saracoglu, F., Engin, I., \& Ejder, H. L. (2014). Maliye Ders Notları. Gazi Kitabevi.

Taylor, J. W. (2003). "Short-Term Electricity Demand Forecasting Using Double Seasonal Exponential Smoothing", Journal of the Operational Research Society, 54, pp. 799-805. 
Lorek, K. S. \& Mckeown, J. C. (1978). "The Effect on Predictive Ability of Reducing the Number of Observations on a Time-Series Analysis of Quarterly Earnings Data", Journal of Accounting Research, 16, pp. 204-214.

Lusk, E. J. \& Neves, J. S. (1984). A Comparative Arima Analysis of The 111 Series of the Makridakis Competition", Journal of Forecasting, 3, pp. 329-332.

Makridakis, S. \& Hibon, M. (1997). "ARMA Models and the Box-Jenkins Methodology", Journal of Forecasting, 16, pp. 147-163.

Makridakis, S., Hibon, M. \& Moser, C. (1979). "Accuracy of Forecasting: An Empirical Investigation” Journal of the Royal Statistical Society, Series A (General), 142, pp. 97-145.

Winters, P. R. (1960). "Forecasting Sales By Exponentially Weighted Moving Averages", Man. Sci, 6, pp. 324-342.

Yılmaz, E. (2019). "Vergi Gelirlerinin Tahminlenmesine Yönelik Ekonometrik Model”, Vergi Dünyası, 38 (449), ss. 38-47. 